\title{
Disease Response Evaluator Identifier
}

National Cancer Institute

\section{Source}

National Cancer Institute. Disease Response Evaluator Identifier. NCI Thesaurus. Code C117392.

A sequence of characters used to identify, name, or characterize the evaluator of the disease response. 